\title{
Influence of Age on Frequency of Vancomycin Dosing
}

\author{
Michael Legal and Marisa Wan
}

\begin{abstract}
Background: Vancomycin is commonly prescribed at the authors' institution because of a high prevalence of invasive infections caused by methicillin-resistant Staphylococcus aureus (MRSA) in a generally younger population. The most commonly prescribed empiric dosing interval is every $12 \mathrm{~h}$ (q12h). However, observations have suggested that younger adult patients require more frequent dosing, such as every $8 \mathrm{~h}$ (q8h). Initial underdosing of vancomycin may increase the risk of antibiotic failure.
\end{abstract}

Objective: To determine whether patients under 40 years of age are more likely than older patients to require $\mathrm{q} 8 \mathrm{~h}$ dosing of vancomycin and whether recommendations can be made to alter current prescribing practices.

Methods: This retrospective unmatched case-control study involved patients who had received vancomycin for suspected or confirmed severe MRSA infections. The cases were patients who had been confirmed as requiring $\mathrm{q} 8 \mathrm{~h}$ dosing, and the controls were patients who had been confirmed as requiring $\mathrm{q} 12 \mathrm{~h}$ dosing (on the basis of target predose serum levels). The influence of age (the predictor variable) on outcome (the vancomycin regimen) was evaluated by logistic regression.

Results: The odds ratio for patients under 40 years of age requiring q8h dosing was 3.1 (95\% confidence interval 1.5-6.3) $(p=0.002)$. Sixty percent of patients under 40 ultimately required a $\mathrm{q} 8 \mathrm{~h}$ regimen to achieve target predose serum levels. Patients who required q8h dosing took longer to achieve their first therapeutic serum level than those with q12h dosing (median 6 versus 4 days; $p<0.001$ ).

Conclusions: In this patient population, age less than 40 years was a strong predictor for requiring more frequent dosing of vancomycin. The authors suggest that doses of $15 \mathrm{mg} / \mathrm{kg}$ IV q8h be used empirically for younger patients with severe infections and normal renal function.

Key words: vancomycin, methicillin-resistant Staphylococcus aureus, pharmacokinetics, pharmacodynamics, dosing

\section{RÉSUMÉ}

Contexte : La vancomycine est couramment prescrite à l'établissement des auteurs à cause de la prévalence élevée d'infections envahissantes à Staphylococcus aureus résistant à la méthicilline (SARM) dans une population de patients généralement plus jeunes. L'intervalle posologique empirique le plus souvent prescrit est de 12 heures (q12h). Cependant, des observations ont permis de constater que les plus jeunes adultes requièrent des fréquences d'administration plus rapprochées, comme toutes les huit heures (q8h). Un intervalle posologique initial insuffisamment rapproché pourrait donc accroître le risque d'échec de l'antibiothérapie par la vancomycine.

Objectif : Déterminer si les patients de moins de 40 ans sont plus susceptibles que les patients plus âgés d'avoir besoin d'une fréquence d'administration de la vancomycine toutes les 8 heures et si on peut formuler des recommandations visant à modifier les habitudes de prescription actuelles.

Méthodes : Cette étude rétrospective de cas-témoins non appariés est fondée sur des patients qui avaient reçu de la vancomycine pour une infection à SARM confirmée ou soupçonnée. Les cas consistaient en des patients pour lesquels on avait confirmé le besoin d'une fréquence d'administration q8h et les témoins étaient des patients pour lesquels on avait confirmé le besoin d'une fréquence d'administration q12h (d'après les concentrations sériques résiduelles cibles). L'influence de l'âge (la variable prédictive) sur les résultats (le régime posologique de la vancomycine) a été évaluée à l'aide d'une analyse de régression logistique.

Résultats : Le risque relatif approché pour les patients de moins de 40 ans qui avaient besoin d'une fréquence d'administration q8h était de 3,1 (intervalle de confiance à $95 \%: 1,5-6,3)(p=0,002)$. Soixante pour cent de ces patients ont finalement nécessité une fréquence d'administration $\mathrm{q} 8 \mathrm{~h}$ afin d'atteindre les concentrations sériques résiduelles souhaitées. Les patients qui avaient besoin d'une fréquence d'administration $\mathrm{q} 8 \mathrm{~h}$ ont atteint moins rapidement leur première concentration sérique thérapeutique que ceux dont la fréquence d'administration était $\mathrm{q} 12 \mathrm{~h}$ (nombre médian de 6 jours contre 4 jours, respectivement; $p<0.001$ ).

Conclusions : Un âge inférieur à 40 ans s'est révélé être un puissant facteur de prédiction du besoin de recourir à une fréquence d'administration de la vancomycine plus rapprochée dans cette population. Les auteurs suggèrent l'utilisation empirique de doses de $15 \mathrm{mg} / \mathrm{kg}$ i.v. q8h chez les patients plus jeunes souffrant d'infections graves et dont la fonction rénale est normale.

Mots clés : vancomycine, Staphylococcus aureus résistant à la méthicilline, pharmacocinétique, pharmacodynamique, intervalle posologique

[Traduction par l'éditeur] 


\section{INTRODUCTION}

$\mathrm{V}$ ancomycin is the drug of choice for hospital inpatients with severe methicillin-resistant Staphylococcus aureus (MRSA) infections. ${ }^{1}$ Although vancomycin is an effective bactericidal agent, literature reports of antibiotic failure with this drug are relatively common. ${ }^{2}$ Efforts to minimize the risk of antibiotic failure have led to a focus on how best to optimize vancomycin pharmacokinetics.

The predose level of vancomycin in the serum is believed to be the most relevant clinically measurable pharmacokinetic parameter because the killing of susceptible organisms by this drug is time-dependent. ${ }^{3,4}$ As such, the bactericidal effect is related to the time above the minimum inhibitory concentration (MIC). ${ }^{1}$ Although target predose serum levels have traditionally been $5-15 \mathrm{mg} / \mathrm{L},{ }^{3}$ there has been a trend among clinicians and in guidelines to target higher predose levels. For example, higher levels (15-20 mg/L) and more frequent dosing for patients with normal renal function were endorsed by the recent guidelines of the Infectious Diseases Society of America. ${ }^{5}$

Theoretical rationales for higher targets include known poor tissue penetration of vancomycin into the lung, central nervous system, and bone. ${ }^{6}$ Also of concern is the apparently greater rate of treatment failure among patients with $S$. aureus isolates having a higher MIC. ${ }^{7}$ However, the results of recent clinical studies have been mixed. Jeffres and others ${ }^{8}$ found that targeting higher predose serum levels did not seem to improve outcomes in patients with health-care-associated pneumonia. Conversely, Hidayat and others' observed a $20 \%$ lower response rate among patients with MRSA pneumonia or bacteremia who did not initially achieve the target predose serum level $(\geq 15 \mathrm{mg} / \mathrm{L})$. In addition, patients infected with high-MIC MRSA strains (MIC $\geq 2 \mathrm{mg} / \mathrm{L}$ ) and those with invasive infections were less likely to have a response to treatment. ${ }^{9}$

The debate about vancomycin target levels is particularly relevant at the authors' institution because of the high prevalence of invasive MRSA infections in the patient population. At the time that this study was conducted, most clinicians at the study institution had adopted the higher target predose levels for vancomycin (mostly $10-15 \mathrm{mg} / \mathrm{L}$ ) for severe infections such as meningitis, pneumonia, endocarditis, osteomyelitis, and sepsis. Interestingly, despite the general practice of targeting higher predose serum levels in the past 7 or 8 years, the approach to initial vancomycin dosing had remained largely unchanged. Anecdotal observation suggested that by far the most common initial regimen prescribed was $1 \mathrm{~g} \mathrm{IV}$ every $12 \mathrm{~h}$ (q12h); however, clinical pharmacists at this institution usually corrected the dose to reflect the patient's weight, using $15 \mathrm{mg} / \mathrm{kg}$ to guide empiric dosing.

It was observed that lower-than-desired initial steadystate predose serum levels (less than $10 \mathrm{mg} / \mathrm{L}$, and often less than $5 \mathrm{mg} / \mathrm{L}$ ) occurred more frequently in adult patients in their 20s and 30s than in patients in their 40s and older. In most cases, the only logical way to achieve the target predose levels was to change the dosing frequency to every $8 \mathrm{~h}$ (q8h), rather than adjusting the dose. As a result, for a high proportion of this patient group, $\mathrm{q} 8 \mathrm{~h}$ dosing was ultimately continued for the management of their infection. The challenge lies in promptly identifying the patients who will ultimately require $\mathrm{q} 8 \mathrm{~h}$ dosing.

Although it would seem logical to empirically adjust the dosing interval according to the patient's renal function, by calculating the creatinine clearance (for which the modified Cockcroft-Gault equation ${ }^{10}$ is used at the authors' institution), there are difficulties with this approach. Serum creatinine can fluctuate significantly within the "normal range" for patients admitted with these acute infections. Furthermore, serum creatinine is often somewhat elevated at the time of admission because of volume depletion and acute illness. It usually normalizes with volume replacement, but this is not usually confirmed until $24 \mathrm{~h}$ after admission. In addition, serum creatinine can be altered by diet, muscle mass, and acute illness. ${ }^{11}$ Many patients admitted to the authors' institution have comorbidities, such as HIV infection or poor nutritional status, that can contribute to muscle wasting. In those patients, serum creatinine may not provide a good measure of renal function, since it typically overestimates creatinine clearance. Finally, the hospital's vancomycin dosing nomogram (like many nomograms used elsewhere) did not suggest dosing intervals any more frequent than $\mathrm{q} 12 \mathrm{~h}$, regardless of creatinine clearance. This made it difficult for clinicians to know when empiric $\mathrm{q} 8 \mathrm{~h}$ dosing was indicated. For these reasons, the authors believed that age might be a more reliable predictor of appropriate vancomycin dosing frequency for patients with apparently normal renal function.

The hypothesis was that adult patients under 40 years of age eliminate vancomycin more quickly than older patients and are more likely to require $\mathrm{q} 8 \mathrm{~h}$ dosing to achieve target predose serum levels. The age of 40 years was arbitrarily chosen as the cut-off between older and younger patients on the basis of clinical experience and observation. It was believed that patients less than 40 years of age might be at risk for suboptimal outcomes through delays in achieving adequate serum levels of the drug, as a result of insufficient initial dosing. This factor is even more relevant now that recommended targets have been increased to $15-20 \mathrm{mg} / \mathrm{L}$ for the infections discussed in this paper. ${ }^{5}$ Therefore, this study was undertaken to determine whether younger patients (less than 40 years of age) were more likely than patients 40 years of age or older to need $\mathrm{q} 8 \mathrm{~h}$ dosing and whether recommendations could be made to alter prescribing practices as a way to optimize vancomycin therapy. 


\section{METHODS}

A retrospective unmatched case-control study was conducted to examine vancomycin dosing frequency as a function of age. The study was conducted at St Paul's Hospital, a 520-bed acute care teaching hospital located in downtown Vancouver. The pharmacy's computer system was used to identify patients admitted to the hospital between October 2002 and August 2006 for whom vancomycin was prescribed. Candidate charts were then screened for inclusion and exclusion criteria. For patients with multiple eligible admissions, only the most recent admission was included in the study.

The major inclusion criteria were severe infection, including suspected or confirmed osteomyelitis, sepsis, bacteremia, pneumonia, endocarditis, or meningitis; MRSA as the suspected or confirmed causative pathogen; normal renal function, defined as creatinine clearance above $90 \mathrm{~mL} / \mathrm{min}$ per $70 \mathrm{~kg}$, measured within $48 \mathrm{~h}$ of starting vancomycin; vancomycin therapy for more than 2 days, with a dosing regimen of either $\mathrm{q} 12 \mathrm{~h}$ or $\mathrm{q} 8 \mathrm{~h}$; and age above 18 years. The appropriateness of the regimen had to have been confirmed by a predose serum concentration of vancomycin within the target range. When this study was conducted, the most commonly accepted target at the institution was $10-15 \mathrm{mg} / \mathrm{L}$.

At the time of this study, physicians at the study institution ordered the initial vancomycin regimen, after which pharmacists provided pharmacokinetic monitoring and adjusted the vancomycin dose and/or dosing interval as required. For the severe infections listed above, the pharmacists would typically order measurement of a predose serum level within the first few days of therapy to confirm therapeutic efficacy.

The major exclusion criteria were infection at a site not described as being included, duration of vancomycin therapy less than 2 days, serum creatinine level not available, and cystic fibrosis.

Cases were defined as patients who were confirmed as requiring $\mathrm{q} 8 \mathrm{~h}$ dosing. Controls were patients who were confirmed as requiring $\mathrm{q} 12 \mathrm{~h}$ dosing. The intended enrolment was 2 controls for each case.

The primary outcome was the odds ratio (OR) of patients less than 40 years of age requiring more frequent vancomycin dosing (specifically $\mathrm{q} 8 \mathrm{~h}$ dosing instead of $\mathrm{q} 12 \mathrm{~h}$ ) relative to patients 40 years or older. The influence of other variables, including concurrent nephrotoxic drugs, diabetes mellitus, and sex, on the vancomycin regimen was also explored.

Additional secondary outcomes were empiric dosing regimen, average vancomycin dose, regimen required by age group, time until first therapeutic level, frequency of creatinine increase by greater than $30 \%$ above baseline during vancomycin therapy, frequency of regimen change due to a high predose serum level or creatinine increase by greater than
$30 \%$ above baseline during vancomycin therapy, and professional responsible for making the dosing change.

The study was conducted with ethics approval from the University of British Columbia - Providence Health Care Research Ethics Board.

\section{Statistical Analysis}

Sample size was determined on the basis of a predicted OR of 3 , with a desired power of $80 \%$ and $\alpha$ of 0.05 . It was estimated that 100 controls and 50 cases (2:1 ratio) would be required. However, because of difficulty in locating an adequate number of controls, the ratio of cases to controls was changed to $1: 1$, which resulted in a new estimated sample size of 64 patients per group.

The primary outcome was calculated using a logistic regression model, with age category (less than 40 years versus greater than or equal to 40 years) as the predictor variable. The influence of other potential variables, specifically use of concurrent nephrotoxic drugs (aminoglycosides, angiotensinconverting enzyme inhibitors, nonsteroidal anti-inflammatory drugs), diabetes mellitus, and sex, was also explored with this model.

The Student $t$ test was used to compare differences in mean age, mean baseline serum creatinine, mean baseline creatinine clearance (as calculated by the modified CockcroftGault formula), and mean vancomycin dose per interval received by each group. Baseline serum creatinine was the value of serum creatinine measured closest to the time of initiation of vancomycin. The Mann-Whitney $U$ test was used to assess differences between the cases and controls with respect to time until achievement of first therapeutic level. The $\chi^{2}$ test was used to assess differences between the 2 groups in terms of increase in serum creatinine above $30 \%$ and regimen change secondary to increase in serum creatinine above $30 \%$ or accumulation of vancomycin. Descriptive statistics were used to report the proportion of patients for whom each regimen was prescribed empirically, the proportion of patients in each age category requiring each regimen, and the professional responsible for dosing change.

\section{RESULTS}

A total of 131 patients were included in the study: 58 cases in the $\mathrm{q} 8 \mathrm{~h}$ group and 73 controls in the $\mathrm{q} 12 \mathrm{~h}$ group. The authors believe that these groups represented the entire population of eligible patients during the study period, because it was not possible to identify any additional eligible patients for the timeframe in question.

The most obvious difference between the groups at baseline related to age (Table 1): the mean age of the cases was nearly 10 years younger than that of the controls. This is 
Table 1. Characteristics of Patients Receiving Vancomycin for Specified Infections

\begin{tabular}{|c|c|c|}
\hline \multirow[b]{2}{*}{ Characteristic } & \multicolumn{2}{|c|}{ Dosing Interval; No. (\%) of Patients* } \\
\hline & Cases: q8h $(n=58)$ & Controls: $q 12 \mathrm{~h}(n=73)$ \\
\hline \multicolumn{3}{|l|}{ Demographic } \\
\hline Age (years) (mean \pm SD) & $39 \pm 11.3$ & $47 \pm 15.0$ \\
\hline Sex (males) & $47 \quad(81)$ & $53(73)$ \\
\hline Weight $(\mathrm{kg})($ mean $\pm \mathrm{SD}) \dagger$ & $72.6 \pm 12.9$ & $75.9 \pm 21.2$ \\
\hline \multicolumn{3}{|l|}{ Admission ward } \\
\hline General medicine & $33(57)$ & $42(58)$ \\
\hline Other & $25(43)$ & $31(42)$ \\
\hline \multicolumn{3}{|l|}{ Risk factors for infection } \\
\hline Injection drug user & $33(57)$ & $27(37)$ \\
\hline HIV-positive & 21 (36) & $25(34)$ \\
\hline Taking immunosuppressants & $0(0)$ & $3(4)$ \\
\hline With colonization by MRSA & $18(31)$ & $21(29)$ \\
\hline \multicolumn{3}{|l|}{ Comorbidities } \\
\hline Diabetes mellitus & $2(3)$ & $4(5)$ \\
\hline Hypertension & $1(2)$ & $10(14)$ \\
\hline Congestive heart failure & $0(0)$ & $3(4)$ \\
\hline Cancer & $2(3)$ & $5(7)$ \\
\hline Hepatitis C & $33(57)$ & $35(48)$ \\
\hline \multicolumn{3}{|l|}{ Hospital course } \\
\hline Admission to ICU & $13(22)$ & $13(18)$ \\
\hline \multicolumn{3}{|c|}{ Concurrent nephrotoxic medications§ } \\
\hline Aminoglycosides & $13(22)$ & $3(4)$ \\
\hline ACE inhibitors & $4(7)$ & $9(12)$ \\
\hline NSAIDs & $17(29)$ & $23(32)$ \\
\hline \multicolumn{3}{|l|}{ Infection } \\
\hline Bacteremia & 11 (19) & $14(19)$ \\
\hline Osteomyelitis & $20(34)$ & $27(37)$ \\
\hline Pneumonia & $9(16)$ & $16(22)$ \\
\hline Sepsis & $6(10)$ & $8(11)$ \\
\hline Meningitis & $3(5)$ & $0(0)$ \\
\hline Endocarditis & $9(16)$ & $8(11)$ \\
\hline Positive results on culture & $15(26)$ & $16(22)$ \\
\hline \multicolumn{3}{|c|}{$\begin{array}{l}\text { Baseline creatinine clearance } \\
(\mathrm{mL} / \mathrm{min} \text { per } 70 \mathrm{~kg})(\text { mean } \pm \mathrm{SD}) \|\end{array}$} \\
\hline Age $<40$ years & $168.1 \pm 48.1$ & $166.6 \pm 47.1$ \\
\hline Age $\geq 40$ years & $151.7 \pm 54.9$ & $132.6 \pm 32.2$ \\
\hline \multicolumn{3}{|c|}{$\begin{array}{l}\text { ACE = angiotensin-converting enzyme, ICU = intensive care unit, MRSA = methicillin-resistant } \\
\text { Staphylococcus aureus, NSAID = nonsteroidal anti-inflammatory drug, SD = standard deviation. } \\
\text { *Unless indicated otherwise. } \\
\text { +Weights were available for } 15 \text { patients receiving } q 12 \mathrm{~h} \text { dosing and } 16 \text { patients receiving q8h } \\
\text { dosing. } \\
\text { fOther admission wards were HIV, surgery, cardiology, intensive care unit, cardiac surgery } \\
\text { intensive care unit, geriatrics, and orthopedics. } \\
\text { §One patient in the q12h group was receiving amphotericin B, one patient in the q8h group } \\
\text { was exposed to contrast dye, and no patients in either group had received } \\
\text { tacrolimus-cyclosporine. } \\
\text { ICalculated using the modified Cockcroft-Gault formula: creatinine clearance }(\mathrm{mL} / \mathrm{min} \text { per } \\
70 \mathrm{~kg})=[(140-\text { age }) \times 90] / \mathrm{SCr}(\mu \mathrm{mol} / \mathrm{L}), \text { where } \mathrm{SCr}=\text { serum creatinine level. }{ }^{10}\end{array}$} \\
\hline
\end{tabular}


consistent with the research hypothesis that age influenced vancomycin regimen. Patients in the control group had a higher incidence of hypertension (Table 1), whereas a history of injection drug use was more common in the case group.

The most common confirmed or suspected MRSA infection among patients included in the study was osteomyelitis, followed by bacteremia and pneumonia. However, a positive culture confirming the causative organism was available for only 31 (24\%) of the 131 patients.

Patients less than 40 years of age were more than 3 times as likely as older patients to require q $8 \mathrm{~h}$ dosing (OR 3.1, 95\% CI $1.5-6.3 ; p=0.002)$. Thirty-three $(57 \%)$ of the 58 cases were less than 40 years old, and 22 (30\%) of the 73 controls were less than 40 years old. The logistic regression model was adjusted to take into account predictor variables (concurrent nephrotoxic drugs, diabetes, and sex). Because few or no patients had prescriptions for tacrolimus, cyclosporine, amphotericin $\mathrm{B}$, or contrast dye, these agents were excluded from the logistic regression model.

Use of an aminoglycoside was the only variable that was significantly associated with the outcome. Patients with a prescription for an aminoglycoside were more likely to receive q8h dosing than patients without such a prescription (OR 6.7, 95\% CI 1.8-25; $p=0.004$ ).

For 7 patients $(5 \%)$, the vancomycin was prescribed for empiric q8h dosing, whereas 123 patients (94\%) had prescriptions for empiric $\mathrm{q} 12 \mathrm{~h}$ dosing (Table 3 ). The remaining patient $(1 \%)$ had a prescription for empiric q18h dosing. The average dose per interval was significantly different between the 2 groups: $1.14 \mathrm{~g}$ (standard deviation [SD] 0.2) per dose for controls and $1.06 \mathrm{~g}$ (SD 0.2) per dose for cases $(p<0.001)$.

The median time from the start of vancomycin therapy until the first therapeutic level was 6 days (interquartile range [IQR] 7.5 days) for patients receiving $\mathrm{q} 8 \mathrm{~h}$ dosing and 4 days (IQR 4.0 days) for those receiving q12h dosing $(p<0.001)$. One hundred and eighteen (90\%) of the patients had a quoted target of $10-15 \mathrm{mg} / \mathrm{L}$. For the remaining 13 patients $(10 \%)$, the targets were $15-20 \mathrm{mg} / \mathrm{L}$ or $10-20 \mathrm{mg} / \mathrm{L}$.
The baseline mean serum creatinine level did not differ between the 2 groups: $58.9 \mu \mathrm{mol} / \mathrm{L}$ (SD 16) for the q8h group and $60.1 \mu \mathrm{mol} / \mathrm{L}$ (SD 17.6) for the $\mathrm{q} 12 \mathrm{~h}$ group $(p=0.578)$. However, the mean baseline creatinine clearance as calculated by the modified Cockcroft-Gault equation was significantly different: $164 \mathrm{~mL} / \mathrm{min}$ per $70 \mathrm{~kg}$ (SD 48.3) for the $\mathrm{q} 8 \mathrm{~h}$ group and $146 \mathrm{~mL} / \mathrm{min}$ per $70 \mathrm{~kg}$ (SD 41.8) for the $\mathrm{q} 12 \mathrm{~h}$ group $(p=0.026)$.

A follow-up serum creatinine value was available for 130 of the 131 patients. Of the 58 patients in the q8h group, 20 (34\%) experienced an increase in creatinine greater than $30 \%$. Of the 72 patients in the $\mathrm{q} 12 \mathrm{~h}$ group for whom a follow-up serum creatinine value was available, 22 (31\%) experienced a rise in creatinine greater than $30 \%$; for one patient in the $\mathrm{q} 12 \mathrm{~h}$ group, no follow-up serum creatinine value was available. Thirteen (22\%) of the patients in the q8h group and 14 (19\%) of those in the $\mathrm{q} 12 \mathrm{~h}$ group required a change in regimen because of increased predose serum vancomycin level or increased serum creatinine. However, none of these differences were statistically significant.

Pharmacists were the professionals responsible for changing the vancomycin regimen to $\mathrm{q} 8 \mathrm{~h}$ in the vast majority of cases $(54 / 58$ or $93 \%)$.

\section{DISCUSSION}

This study was undertaken to determine whether age less than 40 years predicts the need for more frequent vancomycin dosing. In the study population, patients under the age of 40 were 3 times more likely than older patients to require q8h dosing instead of $\mathrm{q} 12 \mathrm{~h}$ dosing.

Of the covariates studied, only a concurrent prescription for aminoglycoside seemed to predict $\mathrm{q} 8 \mathrm{~h}$ dosing. A likely explanation for this finding is that aminoglycosides were commonly prescribed for synergy with other antibiotics for endocarditis. Thus, aggressive vancomycin dosing in endocarditis was associated with, not caused by, aminoglycoside use. In addition, given the unclear evidence for synergy between aminoglycosides and vancomycin, it is likely that this

Table 2. Logistic Regression Model of Effects of Predictor Variables on q8h Dosing

Model* $^{*}$

Patients $<40$ years of age who required q8h

dosing regimen

Patients taking aminoglycosides who required q8h

dosing regiment

$\mathrm{Cl}=$ confidence interval, $\mathrm{OR}=$ odds ratio.

*Predictor variables were diabetes mellitus, sex, and use of aminoglycoside, angiotensin-

converting enzyme inhibitors, and nonsteroidal anti-inflammatory drugs. Too few patients were exposed to amphotericin B, contrast dye, or tacrolimus-cyclosporine to allow analysis by logistic regression.

†No other predictor variables (sex, diabetes mellitus, angiotensin-converting enzyme inhibitors, nonsteroidal anti-inflammatory drugs) had a significant effect on outcome. 
Table 3. Comparison of Clinical Parameters by Dosing Frequency

\begin{tabular}{|c|c|c|c|}
\hline \multirow[b]{2}{*}{ Clinical Parameter } & \multicolumn{3}{|c|}{ Dosing Interval; No. (\%) of Patients* } \\
\hline & Cases: $\mathrm{q} 8 \mathrm{~h}(n=58)$ & Controls: q12h $(n=73)$ & $p$ Value \\
\hline Age (years) (mean \pm SD) & $39 \pm 11.3$ & $47 \pm 15$ & $0.001 \dagger$ \\
\hline Sex (males) & $47 / 58(81)$ & $53 / 73(73)$ & $0.30 \ddagger$ \\
\hline Baseline serum creatinine $(\mu \mathrm{mol} / \mathrm{L})($ mean $\pm \mathrm{SD})$ & $58.9 \pm 16$ & $60.1 \pm 17.6$ & $0.58+$ \\
\hline $\begin{array}{l}\text { Baseline creatinine clearance } \\
(\mathrm{mL} / \mathrm{min} \text { per } 70 \mathrm{~kg})(\text { mean } \pm \mathrm{SD})\end{array}$ & $164 \pm 48.3$ & $146 \pm 41.8$ & $0.026+$ \\
\hline Weight (kg) (mean \pm SD)§ & $72.6 \pm 12.9$ & $75.9 \pm 21.2$ & $0.61 \dagger$ \\
\hline Empiric vancomycin regimen $\|$ & $7 / 131(5)$ & 123/131 (94) & \\
\hline Dose per interval $(\mathrm{g})$ (mean \pm SD) & $1.06 \pm 0.2$ & $1.14 \pm 0.2$ & $<0.001 \dagger$ \\
\hline \multicolumn{4}{|l|}{ Regimen by ageף } \\
\hline$<40(n=55)$ & $33(60)$ & $22(40)$ & \\
\hline$\geq 40(n=76)$ & $25(33)$ & $51(67)$ & \\
\hline Length of stay (days) (median and IQR) & $22(26.3)$ & $19(22.5)$ & \\
\hline $\begin{array}{l}\text { Time from start of vancomycin until first } \\
\text { therapeutic level (days) (median and IQR) }\end{array}$ & $6.0(7.5)$ & $4.0(4.0)$ & $<0.001 * *$ \\
\hline $\begin{array}{l}\text { Increase in creatinine }>30 \% \text { above baseline } \\
\text { while taking vancomycin }\end{array}$ & $20 / 58(34)$ & 22/72 (31) & 0.60†† \\
\hline $\begin{array}{l}\text { Change in vancomycin regimen due to } \\
\text { increase in trough level or serum creatinine }\end{array}$ & $13 / 58(22)$ & $14 / 73(19)$ & 0.65 †† \\
\hline
\end{tabular}

$\mathrm{IQR}=$ interquartile range, $\mathrm{SD}=$ standard deviation

*Unless indicated otherwise

tStudent $t$ test.

\#Fisher exact test.

$\S$ Weights were available for 15 patients receiving q8h dosing and 16 patients receiving q12h dosing.

IIPercentages calculated on the basis of entire study population. For the remaining patient, the prescription

was for empiric q18h dosing.

IPercentages calculated according to $n$ values given in column 1.

**Mann-Whitney $U$ test.

$+\chi^{2}$ test.

combination was prescribed preferentially for younger patients who might better tolerate this nephrotoxic combination.

Another important finding was that $60 \%$ of patients less than 40 years of age ultimately required q8h dosing to achieve the desired predose vancomycin levels. In addition, for those patients who required q8h dosing it took 1.5 times as long to achieve a therapeutic predose level as for patients who required $\mathrm{q} 12 \mathrm{~h}$ dosing. This delay probably represented the time needed to achieve a steady-state predose level and to determine that the $\mathrm{q} 12 \mathrm{~h}$ regimen was inadequate. Given that $\mathrm{q} 8 \mathrm{~h}$ dosing was prescribed empirically in only $5 \%$ of cases, it could be expected that a majority of younger patients with severe MRSA infections would experience this delay.

There is ample evidence to suggest that delays in achieving optimal antibiotic dosing can affect outcomes. Previous studies have shown that a delay in initiating appropriate antibiotic therapy in cases of ventilator-associated pneumonia and S. aureus bacteremia was associated with higher in-hospital mortality. ${ }^{12,13}$ Similarly, it has been demonstrated that appropriate antibiotic therapy within the first hour of sepsis increases survival. ${ }^{14}$ Although Jeffres and others ${ }^{8}$ found that higher trough levels or area-under-the-curve values did not correlate with improved hospital outcome, these authors also admitted that they did not investigate the effect of time to achieve therapeutic levels on patient outcomes.

Although the current study focused on the effects of altered dosing frequency on achieving target predose serum levels of vancomycin, giving an initial loading dose of the drug is also an efficient way to improve serum concentrations early in therapy. However, it will still be through appropriate dosing frequency that adequate steady-state predose levels are maintained.

The relatively high frequency of increased serum creatinine in both groups during vancomycin therapy was most likely a result of the severity of illness in these patients rather than a result of the vancomycin therapy. However, it is possible that the intensity of vancomycin dosing was a contributing factor. Another retrospective study suggested that higher trough levels and prolonged exposure to vancomycin may increase the risk of nephrotoxicity. ${ }^{8}$ However, the patients in that study who were experiencing renal toxicity also had higher Acute Physiology and Chronic Health Evaluation II scores, which made it difficult to differentiate the effect of the underlying disease process on renal function. Another recent study found increased occurrence of nephrotoxicity among patients receiving vancomycin at a dose of $4 \mathrm{~g} /$ day or above. ${ }^{15}$ However, the effects of receiving at least $4 \mathrm{~g} /$ day were studied in only a small 
number of patients. Nevertheless, the current findings underscore the importance of regular monitoring of serum creatinine and judicious ordering of predose drug levels during vancomycin therapy.

The limitations of this study included its retrospective and observational design. Also, the study design prevented assessment of clinical outcomes. We cannot say for certain that age was the only factor influencing the need for $\mathrm{q} 8 \mathrm{~h}$ dosing. We performed basic statistical comparisons of mean age, sex, mean serum creatinine, and mean creatinine clearance (as calculated by the modified Cockcroft-Gault formula) to assess for other potential covariates, but age and mean creatinine clearance were the only 2 variables that differed significantly between the $\mathrm{q} 8 \mathrm{~h}$ and $\mathrm{q} 12 \mathrm{~h}$ groups. Of interest was the fact that serum creatinine was not statistically or clinically different between the groups. Thus, the difference in creatinine clearance was most likely the result of age differences between the groups. This finding supports the original rationale for focusing on age rather than creatinine clearance.

Although the average dose received by the $\mathrm{q} 12 \mathrm{~h}$ group was significantly higher, the clinical significance of this result is unclear. The mean difference in dose between the groups was quite small, amounting to less than the standard dose increment of $250 \mathrm{mg}$. Changes in dose generally have a smaller impact on the predose serum level of a drug than changes in dosing frequency. Thus, this small difference would not be expected to have an impact on the required dosing interval.

Another potential limitation was the inclusion of patients with target ranges between 10 and $20 \mathrm{mg} / \mathrm{L}$. A wide target range could make it more difficult to detect differences in the required dosing interval needed to reach specific narrower targets such as $10-15 \mathrm{mg} / \mathrm{L}$ or $15-20 \mathrm{mg} / \mathrm{L}$. However, we do not believe that this was a large source of "noise" in our study because most patients had a target of $10-15 \mathrm{mg} / \mathrm{L}$, and only a few $(10 \%)$ had targets of $15-20 \mathrm{mg} / \mathrm{L}$ or $10-20 \mathrm{mg} / \mathrm{L}$. In addition, this range accurately reflects local clinical practice at the time of our study with respect to desired targets for severe MRSA infections.

In conclusion, we found that a "one-regimen-fits-all" approach is not appropriate for vancomycin dosing, especially in cases of severe MRSA infection. Educational efforts should be targeted toward physicians and pharmacists to encourage initial dosing of $15 \mathrm{mg} / \mathrm{kg} \mathrm{IV} \mathrm{q8h}$ in adult patients with severe MRSA infections who are younger than 40 years of age and who have normal renal function. In addition, current vancomycin dosing nomograms should be re-evaluated (especially in light of new recommendations to target even higher levels of $15-20 \mathrm{mg} / \mathrm{L}$ ) to ensure that $\mathrm{q} 8 \mathrm{~h}$ dosing is a standard recommendation for younger patients with normal renal function. Further research is needed to establish the most appropriate age and creatinine clearance ranges at which to recommend empiric q $8 \mathrm{~h}$ dosing with the $15-20 \mathrm{mg} / \mathrm{L}$ target.
At a minimum, these measures would reduce workload related to ordering and interpreting unnecessary vancomycin levels. At best, earlier achievement of therapeutic levels might reduce the likelihood of clinical antibiotic failure.

\section{References}

1. Rybak MJ. The pharmacokinetic and pharmacodynamic properties of vancomycin. Clin Infect Dis 2006;42 Suppl 1:S35-S39.

2. Stevens DL. The role of vancomycin in the treatment paradigm. Clin Infect Dis 2006;42 Suppl 1:S51-S57

3. Frighetto L, editor. Providence Health Care formulary and medication prescribing policies. Vancouver (BC): Providence Health Care Pharmacy and Therapeutics Committee; 2006.

4. Saunders NJ. Why monitor peak vancomycin concentrations? Lancet 1994;344(8939-8940):1748-1750.

5. Rybak M, Lomaestro B, Rotschafer JC, Moellering R Jr, Craig W, Billeter $\mathrm{M}$, et al. Therapeutic monitoring of vancomycin in adult patients: a consensus review of the American Society of Health-System Pharmacists, the Infectious Diseases Society of America, and the Society of Infectious Diseases Pharmacists. Am J Health Syst Pharm 2009;66(1):82-98.

6. Mader J, Calhoun J. Osteomyelitis. In: Mandell GL, Bennett JE, Dolin R, editors. Principles and practice of infectious diseases. 5th ed. New York (NY): Elsevier/Churchill Livingstone; 2000. p. 1193.

7. Sakoulas G, Moellering RC Jr. Increasing antibiotic resistance among methicillin-resistant Staphylococcus aureus strains. Clin Infect Dis 2008;46 Suppl 5:S360-S367.

8. Jeffres MN, Isakow W, Doherty JA, McKinnon PS, Ritchie DJ, Micek ST, et al. Predictors of mortality for methicillin-resistant Staphylococcus aureus health-care-associated pneumonia: specific evaluation of vancomycin pharmacokinetic indices. Chest 2006;130(4):947-955.

9. Hidayat LK, Hsu DI, Quist R, Shriner KA, Wong-Beringer A. High-dose vancomycin therapy for methicillin-resistant Staphylococcus aureus infections: efficacy and toxicity. Arch Intern Med 2006;166(19):2138-2144.

10. Dersch D, McCormack J. Estimating renal function for drug dosing: rewriting the gospel? Can J Hosp Pharm 2008;61(2):138-143.

11. Perrone RD, Madias NE, Levey AS. Serum creatinine as an index of renal function: new insights into old concepts. Clin Chem 1992;38(10):1933-1953.

12. Iregui M, Ward S, Sherman G, Fraser V, Marin HK. Clinical importance of delays in the initiation of appropriate antibiotic treatment for ventilator-associated pneumonia. Chest 2002;122(1):262-268.

13. Khatib R, Saeed, S, Sharma M, Riederer K, Fakih MG, Johnson LB. Impact of initial antibiotic choice and delayed appropriate treatment on the outcome of Staphylococcus aureus bacteremia. Eur J Clin Microbiol Infect Dis 2006;25(3):181-185.

14. Kumar A, Roberts D, Wood KE, Light B, Parrillo JE, Sharma S, et al. Duration of hypotension before initiation of effective antimicrobial therapy is the critical determinant of survival in human septic shock. Crit Care Med 2006;34(6):1589-1596.

15. Lodise TP, Lomaestro B, Graves J, Drusano GL. Larger vancomycin doses (at least four grams per day) are associated with an increased incidence of nephrotoxicity. Antimicrob Agents Chemother 2008;52(4):1330-1336.

Michael Legal, BScPharm, PharmD, ACPR, is a Clinical Pharmacy Specialist, Providence Health Care, St Paul's Hospital, Vancouver, British Columbia.

Marisa Wan, BScPharm, ACPR, is a Clinical Pharmacist, Providence Health Care, St Paul's Hospital, Vancouver, British Columbia.

\section{Address correspondence to:}

Dr Michael Legal

Pharmacy

St Paul's Hospital

Providence Health Care

1081 Burrard Street

Vancouver BC V6Z1Y6

e-mail: mlegal@providencehealth.bc.ca 